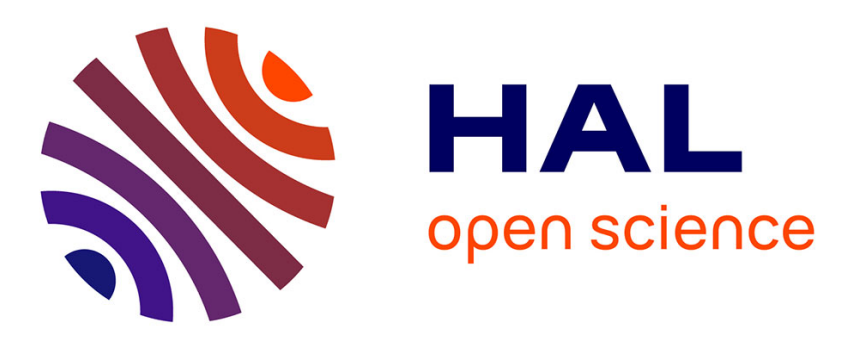

\title{
RAFT Polymerisation of Trifluoroethylene: The importance of understanding reverse additions
}

Vincent Bouad, Marc Guerre, Cédric Totée, Gilles Silly, Olinda Gimello, Bruno Améduri, Jean-Francois Tahon, Rinaldo Poli, Sophie Barrau, Vincent Ladmiral

\section{To cite this version:}

Vincent Bouad, Marc Guerre, Cédric Totée, Gilles Silly, Olinda Gimello, et al.. RAFT Polymerisation of Trifluoroethylene: The importance of understanding reverse additions. Polymer Chemistry, 2021, 12 (15), pp.2271-2281. 10.1039/d0py01754j . hal-03182909

\section{HAL Id: hal-03182909 \\ https://hal.univ-lille.fr/hal-03182909}

Submitted on 9 Apr 2021

HAL is a multi-disciplinary open access archive for the deposit and dissemination of scientific research documents, whether they are published or not. The documents may come from teaching and research institutions in France or abroad, or from public or private research centers.
L'archive ouverte pluridisciplinaire HAL, est destinée au dépôt et à la diffusion de documents scientifiques de niveau recherche, publiés ou non, émanant des établissements d'enseignement et de recherche français ou étrangers, des laboratoires publics ou privés. 


\section{RAFT Polymerisation of Trifluoroethylene: The importance of understanding reverse additions.}

Received 00th January 20xx, Accepted 00th January 20xx

DOI: $10.1039 / x 0 \times x 00000 x$

\section{A. Introduction}

Fluoropolymers possess a set of remarkable properties such as a high thermal stability, chemical resistance, low permittivity but also good weathering durability, hydro- and oleophobicity as well as, in certain cases, electroactivity (ferro-, piezoelectricity). ${ }^{1,2}$ Polyvinylidene fluoride (PVDF) is one of the most used fluoropolymer (second after polytetrafluoroethylene, PTFE). ${ }^{3,4}$ It has found application in filtration membranes, architectural coating and, with its electroactive properties, is a potential candidate for use in high technology devices., 5 The copolymer of vinylidene fluoride (VDF) and trifluoroethylene (TrFE) is a very interesting polymer as it combines the high ferro- and piezoelectric properties of PVDF with a much better processability. In contrast, compared to PVDF, PTrFE has been much less studied. This is likely due to its high price, relative rarity and inferior electroactive properties compared to PVDF or P(VDFco-TrFE). ${ }^{7,8}$

Although TrFE has been widely used and studied as a comonomer (in particular with VDF), only few studies have been dedicated to the homopolymerisation of TrFE. Just like VDF, TrFE only polymerises via the conventional radical

a. ICGM, Université de Montpellier, CNRS, ENSCM, Montpellier, France.

b.IMRCP, Université de Toulouse, CNRS UMR 5623, Université Paul Sabatier, 118

route de Narbonne, 31062 Toulouse Cedex 9, France.

c. Université de Lille, Sciences et Technologies, CNRS, Unité Matériaux Et

Transformations (UMET), F-59000 Lille, France.

d. CNRS, LCC (Laboratoire de Chimie de Coordination), UPS, INPT, Université de

Toulouse, 205 Route de Narbonne, BP 44099, F-31077 Toulouse, Cedex 4, France.

† Footnotes relating to the title and/or authors should appear here.

Electronic Supplementary Information (ESI) available: [details of any supplementary

information available should be included here]. See DOI: 10.1039/x0xx00000x polymerisation mechanism and is prone to chain defects caused by reverse additions (i.e. head-to-head $(\mathrm{HH}$ ) additions and tail-to-tail (TT) additions, where the head and the tail are the $\mathrm{CF}_{2}$ and $\mathrm{CHF}$ groups, respectively; see Figure 10 for the different possible additions). The first studies dedicated to the TrFE radical polymerisation and PTrFE structure by Naylor and Lasoski identified the two main ${ }^{19} \mathrm{~F} N \mathrm{NM}$ resonance regions for the $\mathrm{CFH}$ and $\mathrm{CF}_{2}$ groups and highlighted the spectrum complexity, resulting from the PTrFE multiple stereochemical centres, but did not provide a detailed assignment of the different resonances. ${ }^{9}$ In later work, Yagi described for the first time the PTrFE microstructure and estimated, using the Monte Carlo simulation method, that $50 \%$ of the monomers are backward-added. ${ }^{10}$ Note that Yagi's definition of a backward-added monomer is not identical to the definition of reverse additions used by other authors. A backward-added monomer is a monomer that has been incorporated in the polymer chain via $\mathrm{HH}$ or via a $\mathrm{HH}-\mathrm{TH}$ addition (i.e. via an addition which generates a $-\mathrm{CHF}^{\circ}$ propagating radical). Importantly, a monomer incorporated in the chain via a TT addition is not considered backward-added. In 1982, Cais et al. provided a different estimation of the fraction of reverse additions in PTrFE based on ${ }^{19} \mathrm{~F}$ NMR spectroscopy and rotational isomeric state (RIS) models. ${ }^{11}$ In this article, the authors only considered reverse additions ( $\mathrm{HH}$ and $\mathrm{TT}$ additions). However, they assumed that these reverse additions occurred, as in PVDF, only as the HH-TT addition sequence. They did not consider the possibility of "reverse propagation" (i.e. sequence of tail-to-head (TH) additions). They estimated these HH-TT additions to amount to $11.6 \%$ of the total monomer additions. ${ }^{11}$ In a previous paper using ${ }^{13} \mathrm{C}$ and RIS modelling, which they afterwards deemed erroneous, the same authors had evaluated the fraction of $\mathrm{HH}$-TT defects 
as $50 \% .{ }^{12}$ An update, based on ${ }^{19} \mathrm{~F}\left\{{ }^{1} \mathrm{H}\right\}$ NMR spectra, estimated the $\mathrm{HH}$-TT additions to be $20 \%$ of the overall additions. ${ }^{13}$ More recently, using the definition of reverse additions given by Cais (HH-TT additions sequence), and more modern NMR techniques (higher frequency and more efficient ${ }^{1} \mathrm{H}$ decoupling), Harris reached an estimation of around $13.5 \%{ }^{14}$ To this day, apart from the work of Yagi, the addition defects in PTrFE have only been considered as $\mathrm{HH}$-TT sequence, as in PVDF. Cais and Kometani, for example, described the synthesis of isoregic (HT additions only) PTrFE by dechlorination or debromination of the precursor poly(chlorotrifluoroethylene) (PCTFE) or poly(bromotrifluoroethylene). ${ }^{15}$ They also described the synthesis of pure HH-TT PTrFE by the alternating copolymerisation of 1,2-difluoroethylene and tetrafluoroethylene. $^{16}$ Reversible Deactivation Radical Polymerisation techniques, have not yet been employed to polymerise TrFE. ${ }^{17}$ Several articles report the telomerisation of TrFE using various transfer agents such as hydrogen disulfide ${ }^{18}$, mercaptan and trifluoromethanethiol, ${ }^{19}$ bistrifluoromethyl disulphide, ${ }^{20}$ iodine monochloride, ${ }^{21}$ or dibromodifluoromethane 22,23 for example. Balagué et al. studied the telomerisation of TrFE using fluoroalkyl iodides as transfer agents. ${ }^{24}$ They found that TrFE was less reactive than VDF and that the monoadducts were composed of regularly added and reversely added TrFE unit. ${ }^{24}$ More recently, Gosset et al. used telomerisation to prepare TrFE-dimethyl phosphite monoadducts and obtained the tail $\left(\mathrm{CF}_{2} \mathrm{HCHFPO}_{3}\left(\mathrm{CH}_{3}\right)_{2}\right)$ and head $\left(\mathrm{CFH}_{2} \mathrm{CF}_{2} \mathrm{PO}_{3}\left(\mathrm{CH}_{3}\right)_{2}\right)$ regioisomers in a $3: 1$ ratio. ${ }^{25}$ Finally, Colpaert $^{26}$ et al. prepared PTrFE using the thermal degradation of perfluoro-3-ethyl-2,4-dimethyl-3-pentyl (leading to $\mathrm{CF}_{3} \cdot$ radical) as initiator.

The electroactive properties of PTrFE are highly dependent on the crystal structure. PTrFE is a semi-crystalline polymer with different crystal phases and chain conformations as described by Tashiro et al. ${ }^{27}$ and Lovinger et al. ${ }^{16}$ Oka et al. ${ }^{8}$ reported two crystal phases related to the cooling rate from the melt : the non-polar phase (also called S-phase because of a single peak observed by X-ray diffraction) obtained by quenching, and the polar phase (also called D-phase because of a double peak) obtained by slow cooling from the melt. ${ }^{28}$ The first evidence of ferroelectricity in PTrFE was reported for a polymer cooled at a rate of approximatively $2^{\circ} \mathrm{C} \cdot \mathrm{min}^{-1}{ }^{8}$

This article is the first study of the TrFE RAFT polymerisation. It is a follow-up to the work of Guerre et al. on the RAFT polymerisation of VDF. ${ }^{29-31}$ Those comprehensive studies showed that the $\mathrm{HH}$ reverse additions lead to the formation of less reactivatable $-\mathrm{CH}_{2}$-xanthate-terminated PVDF chains, which impairs the control of the polymerisation. This article examines the behaviour of TrFE under RAFT polymerisation conditions and focusses on the evolution of the PTrFE chain-ends during the polymerisation.

\section{B. Experimental Section}

\section{B.1. Materials}


${ }^{13} \mathrm{C}$ 1D NMR with ${ }^{1} \mathrm{H},{ }^{19} \mathrm{~F}$ and ${ }^{1} \mathrm{H}+{ }^{19} \mathrm{~F}$ Decoupling. A one pulse $90^{\circ}$ pulse sequence was used with $1.1 \mathrm{~s}$ acquisition time, 30 $\mathrm{kHz}$ spectral window 4100 transient and $1 \mathrm{~s}$ recycle delay.

${ }^{19}$ F 2D NMR COSY with ${ }^{1} \mathbf{H}$ Decoupling._The cosygp pulse sequence from Bruker catalog was modified in order to include ${ }^{1} \mathrm{H}$ decoupling over the whole pulse sequence. The acquisition parameters were $1 \mathrm{~s}$ acquisition time, $75 \mathrm{kHz}$ spectral windows in F2 and in F1, 4 transients and recycle delay of $1 \mathrm{~s}$. Processing involved a magnitude calculation phase correction in the F1 dimension.

${ }^{1} \mathbf{H}\left\{{ }^{13} \mathrm{C}\right\}$ 2D NMR HSQC with ${ }^{1} \mathbf{H}$ Decoupling._The hsqcetgpsi2 HSQC pulse sequence from the Bruker catalog was modified in order to apply ${ }^{19} \mathrm{~F}$ decoupling over the whole pulse sequence. Acquisition parameters were $0.3 \mathrm{~s}$ acquisition time, $7.5 \mathrm{kHz}$ spectral window in $\mathrm{F} 2,25 \mathrm{~ms}$ acquisition time, 30.2 $\mathrm{kHz}$ spectral window in $\mathrm{F} 1,{ }^{1} \mathrm{~J}_{\mathrm{CH}}=152 \mathrm{~Hz}$, garp decoupling for ${ }^{13} \mathrm{C}, 8$ transients and recycle delay of $1 \mathrm{~s}$. Processing involved an exponential window multiplication in both dimensions.

${ }^{19} \mathrm{~F}\left\{{ }^{13} \mathrm{C}\right\}$ 2D NMR HSQC with ${ }^{1} \mathbf{H}$ Decoupling._The pulse sequence described by Li et al. ${ }^{33}$ (2D NMR studies of a model for Krytox ${ }^{\circledR}$ perfluoropolyethers) was written from scratch for a Bruker system, the only modifications being ${ }^{1} \mathrm{H}$ decoupling over the whole pulse sequence, ${ }^{13} \mathrm{C}$ decoupling performed with nested loops using $0.5 \mathrm{~ms}$ and $1 \mathrm{~ms}$ chirped adiabatic pulses with $30 \mathrm{kHz}$ bandwidth in order to desynchronize and minimize decoupling artefacts and echo-antiecho quadrature detection in F1. Acquisition parameters were $83 \mathrm{~ms}$ acquisition time and $75 \mathrm{kHz}$ spectral window in F2, $99 \mathrm{~ms}$ acquisition time and $10 \mathrm{kHz}$ spectral window in $\mathrm{F} 1,{ }^{1} \mathrm{~J} \mathrm{CF}=260$ $\mathrm{Hz}, 16$ transients and recycle delay of $1 \mathrm{~s}$.

Table 1: Summary of the results for the RAFT syntheses of PTrFE.
Processing involved linear prediction of an exponential window multiplication in both dimensions and a magnitude calculation phase correction in the $\mathrm{F} 1$ dimension.

${ }^{2} \mathrm{~J}_{\mathrm{CF}}=30 \mathrm{~Hz}$ was used for the ${ }^{2} \mathrm{~J}{ }^{19} \mathrm{~F}\left\{{ }^{13} \mathrm{C}\right\} 2 \mathrm{D}$ NMR HSQC with ${ }^{1} \mathrm{H}$ Decoupling.

Differential Scanning Calorimetry (DSC). DSC experiments were performed on a DSC Q20 apparatus (TA Instruments). PTrFE samples of around $10 \mathrm{mg}$ were analysed in the temperature range $\left[-80,220^{\circ} \mathrm{C}\right]$ at a heating rate of $10^{\circ} \mathrm{C} . \mathrm{min}^{-}$ ${ }^{1}$ under nitrogen gas flow.

X-ray scattering. Wide Angle X-ray Scattering (WAXS) experiments were carried out using a Xeuss 2.0 (XENOCS) with a GeniX3D microsource $(\lambda=1.54 \AA$ ) operating at $0.6 \mathrm{~mA}$ and 50 $\mathrm{kV}$. The sample-to-detector distance was $120 \mathrm{~mm}$.

\section{B.4. Syntheses}

Pressure reactor procedure. The PTrFE used for NMR analyses was synthesized by RAFT polymerisation in a $50 \mathrm{~mL}$ Hastelloy Parr autoclave system (HC 276), equipped with a mechanical Hastelloy stirring system, a 3000-psi rupture disk, inlet and outlet valves, and a Parr electronic controller to regulate the stirring speed and heating. Prior to reaction, the autoclave was pressurised with 30 bars of nitrogen to check for leaks. The autoclave was then kept under vacuum $\left(2010^{-3}\right.$ bar) for 30 minutes to remove any trace of oxygen. A degassed solution of tert-amyl peroxy-2-ethylhexanoate, the initiator (0.281 g, $\left.1.2210^{-3} \mathrm{~mol}\right)$, and CTAXA (1.27 g, $\left.6.0910^{-3} \mathrm{~mol}\right)$ were introduced via a funnel under vacuum. The reactor was then cooled using a liquid nitrogen bath and $10 \mathrm{~g}$ of TrFE was transferred by double weighing (i.e. mass difference before and after filling the autoclave with TrFE). After warming to ambient temperature, the autoclave was heated to the target temperature under mechanical stirring. The reaction was

\begin{tabular}{|c|c|c|c|c|c|c|c|c|c|}
\hline Entry & {$[\text { TrFE }]_{0}:[\text { CTA }]_{0}:[1]_{0}$} & $\begin{array}{c}\text { Time } \\
\text { (h) }\end{array}$ & $\begin{array}{c}\text { Conversion } \\
\text { (\%) }\end{array}$ & $\begin{array}{c}\mathrm{M}_{\mathrm{n}} \text { (theo) } \\
(\mathrm{g} / \mathrm{mol})\end{array}$ & $\begin{array}{c}M_{n}{ }^{f}(\exp ) \\
(g / m o l)\end{array}$ & Đ & $\begin{array}{c}\text {-CFH-XA } \\
(\%)^{c}\end{array}$ & $\begin{array}{c}-\mathrm{CF}_{2}-\mathrm{XA} \\
(\%)^{\mathrm{d}}\end{array}$ & $\begin{array}{c}\text { Irreversible } \\
\text { transfer } \\
(\%)^{\mathrm{e}}\end{array}$ \\
\hline $1^{\mathrm{a}}$ & $50: 1: 0.2$ & 1 & / & / & / & / & l & / & / \\
\hline 2 & $50: 1: 0.2$ & 2 & 4.6 & 400 & 1,700 & 1.01 & 54.5 & 45.5 & 0 \\
\hline 3 & $50: 1: 0.2$ & 4 & 15.3 & 840 & 2,900 & 1.19 & 94.5 & 3.4 & 2.1 \\
\hline 4 & $50: 1: 0.2$ & 6 & 40.6 & 1,900 & 4,600 & 1.32 & 80.1 & 0 & 19.9 \\
\hline 5 & $50: 1: 0.2$ & 15 & 56.6 & 2,500 & 5,700 & 1.58 & 56.3 & 0 & 43.7 \\
\hline $6^{a}$ & $100: 1: 0.2$ & 1 & / & / & / & / & / & / & / \\
\hline 7 & $100: 1: 0.2$ & 2 & 4.3 & 560 & 2,100 & 1.06 & 74 & 24 & 2 \\
\hline 8 & $100: 1: 0.2$ & 4 & 33.6 & 2,900 & 6,300 & 1.37 & 76.7 & 0 & 23.3 \\
\hline 10 & $100: 1: 0.2$ & 8 & 48.3 & 4,200 & 8,000 & 1.39 & 54.9 & 0 & 45.1 \\
\hline 11 & $100: 1: 0.2$ & 15 & 67 & 5,700 & 9,900 & 1.58 & 30.7 & 0 & 69.3 \\
\hline 12 & $50: 0: 0.2$ & 15 & 79 & 3,500 & 5,700 & 4.30 & / & / & / \\
\hline $13^{b}$ & $20: 1: 0.2$ & 0.5 & 2.5 & / & / & / & / & / & / \\
\hline
\end{tabular}

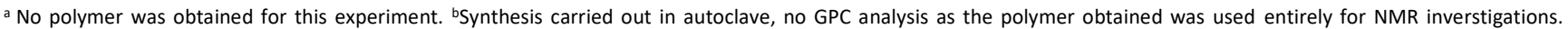
cProportions calculated considering both the $\mathrm{H}$ - and T-adducts (regular and reverse monoadducts respectively). Calculated using equation S1. ${ }^{\mathrm{d}} \mathrm{Calculated}$ using equation S2. ${ }^{e}$ Calculated using equation S3. The chain-end proportions take the monoadducts into account. ${ }^{\mathrm{f}} \mathrm{GPC}$ traces presented Figure S6 and S7. 
stopped after $30 \mathrm{~min}$. The autoclave was cooled to room temperature (ca. $20^{\circ} \mathrm{C}$ ), purged from the residual monomers, and the dimethylcarbonate was removed under vacuum. The crude product was dissolved in $10 \mathrm{~mL}$ of acetone and left under vigorous stirring for $10 \mathrm{~min}$. This polymer solution was then precipitated from $100 \mathrm{~mL}$ of chilled hexane. The precipitated polymer (yellow wax) was filtered through a filter funnel and dried under vacuum (15 $10^{-3}$ mbar) for $2 \mathrm{~h}$ at 40 ${ }^{\circ} \mathrm{C}$. The polymerisation yield $(2.5 \%)$ was determined gravimetrically (mass of dried precipitated polymers/mass of monomer introduced in the pressure reactor).

Carius tube procedure. The RAFT polymerisation of TrFE was carried out in thick $8 \mathrm{~mL}$ Carius tubes in which a solution of the initiator tert-amyl peroxy-2-ethylhexanoate (Trigonox ${ }^{\circledR}$ 121) and CTAXA in DMC ( $5 \mathrm{~mL})$, was added and then degassed by performing at least three freeze-pump-thaw cycles. The gaseous monomer was introduced into the Carius tube at the liquid nitrogen temperature ( $\operatorname{TrFE}, 1.5 \mathrm{~g}, 1.8310^{-2} \mathrm{~mol}, 0.8 \Delta \mathrm{P}$ ) using a custom-made manifold that enables accurate measurement of the gas amounts (using "pressure drop vs. mass of monomer" calibration curves). The tube was then sealed under dynamic vacuum at the liquid nitrogen temperature, before being placed horizontally in a shaking water bath thermostated at $73{ }^{\circ} \mathrm{C}$. At the desired polymerisation time $(1 \mathrm{~h}, 2 \mathrm{~h}, 4 \mathrm{~h}, 6 \mathrm{~h}, 8 \mathrm{~h}$ and $15 \mathrm{~h})$, the tubes were placed into liquid nitrogen, opened, and then the dimethyl carbonate was evaporated at $40{ }^{\circ} \mathrm{C}$ under reduced pressure. Conversions were determined gravimetrically after drying under vacuum until constant weight.

\section{B.5. Computational details}

The computational work was carried out using the Gaussian09 suite of programs. ${ }^{34}$ The geometry optimizations were performed in the gas phase without any symmetry constraint using the B3PW91 functional in combination with the $6-31 G(d, p)$ basis functions for all atoms. The unrestricted formulation was used for all radicals, yielding negligible spin contamination in all cases. The ZPVE, PV, and TS corrections at 298.15 and at $343.15 \mathrm{~K}$ were obtained with Gaussian09 from the solution of the nuclear equation using the standard ideal gas and harmonic approximations, which also verified the nature of all optimized geometries as local minima or firstorder saddle points. A correction of $1.95 \mathrm{kcal} / \mathrm{mol}$ was applied to all $G$ values to change the standard state from the gas phase (1 atm) to solution (1 M). ${ }^{35}$

\section{Results and discussion}

The conditions for the TrFE RAFT polymerisation were adapted from those used by Guerre et al. ${ }^{31}$ for the RAFT polymerisation of VDF (Figure 1). DMC was chosen over other solvents as it provides higher polymerisation rates and is relatively less prone to $\mathrm{H}$-abstraction than other solvents. ${ }^{36}$ TrFE was expected to behave similarly to VDF. Indeed, TrFE is, like VDF, prone to chain defects as shown in previous studies. ${ }^{10,14,37,38}$

The $\mathrm{HH}$ reverse additions proved to play a crucial role in the RAFT polymerisation of VDF as they were shown to be responsible for the slowdown of the RAFT equilibrium and ultimately for the loss of control. ${ }^{23,30}$ The chain ends formed during the RAFT polymerisation of TrFE and their evolution with conversion were thus examined.

The NMR study of the RAFT polymerisation of TrFE revealed the presence of four characteristic xanthate-terminated chains: i) in the 7.1-7.2 ppm region of the ${ }^{1} \mathrm{H}$ NMR spectrum and in the $-171 /-175 \mathrm{ppm}$ region of the ${ }^{19} \mathrm{~F}$ NMR spectrum assigned to -CFH-XA-terminated chains and ii) in the $-80 /-90$ $\mathrm{ppm}$ region of the ${ }^{19} \mathrm{~F}$ NMR spectrum assigned to $-\mathrm{CF}_{2}-\mathrm{XA}$ terminated chains (Figure 2). In addition, the presence of monoadducts (i.e. molecule formed by insertion of only one TrFE unit in a CTA) was also detected by ${ }^{19} \mathrm{~F}$ NMR (Figure S1). Two monoadducts were observed (Figure S1): the $\mathrm{H}$-adduct formed by addition of the CTA R-group to the TrFE CFH (tail) moiety and the $\mathrm{T}$-adduct resulting from the corresponding addition to the $\mathrm{CF}_{2}$ (head) moiety. A detailed description of these monoadducts and the determination of the chain ends is provided elsewhere. ${ }^{39}$ In the course of the polymerisation the $\mathrm{H}$-adduct disappears very quickly from the reaction medium; it can only be observed at low conversions (up to $15 \%)$. In contrast, the amount of T-adduct decreases more gradually with conversion and still persistent at the end of the reaction. It is possible to see the $T$-adducts as functional chain ends, as they are terminated by a xanthate moiety, or as a xanthate trapping agent, as T-adducts seemed to be poorly

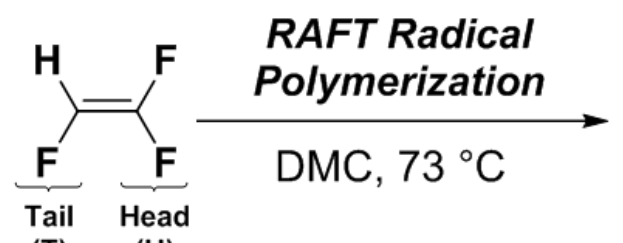

(T) $\quad(\mathrm{H})$

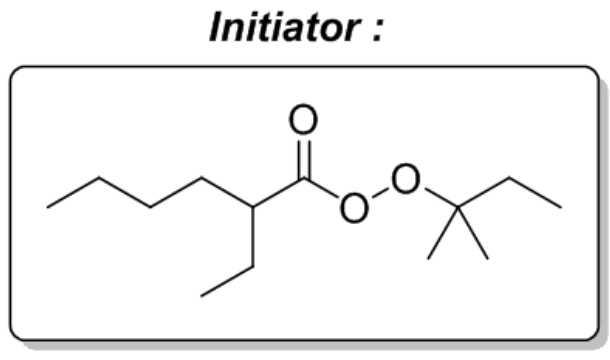

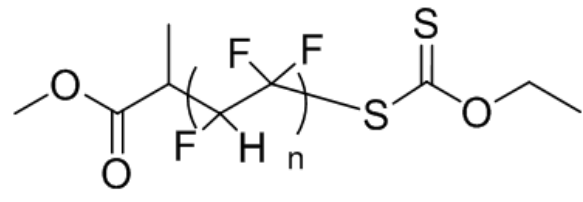

Chain Transfer Agent :

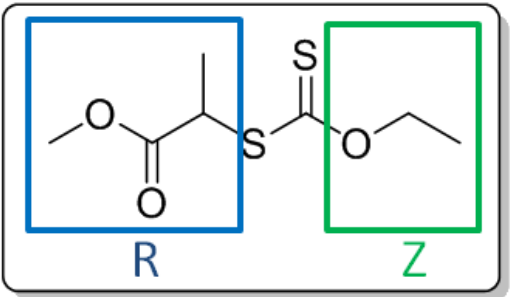

Figure 1. Scheme of the RAFT polymerisation of TrFE, using tert-amyl peroxy-2-ethylhexanoate as initiator, O-ethyl-S-(1-methoxycarbonylethyl)dithiocarbonate as CTA and dimethylcarbonate as solvent. 


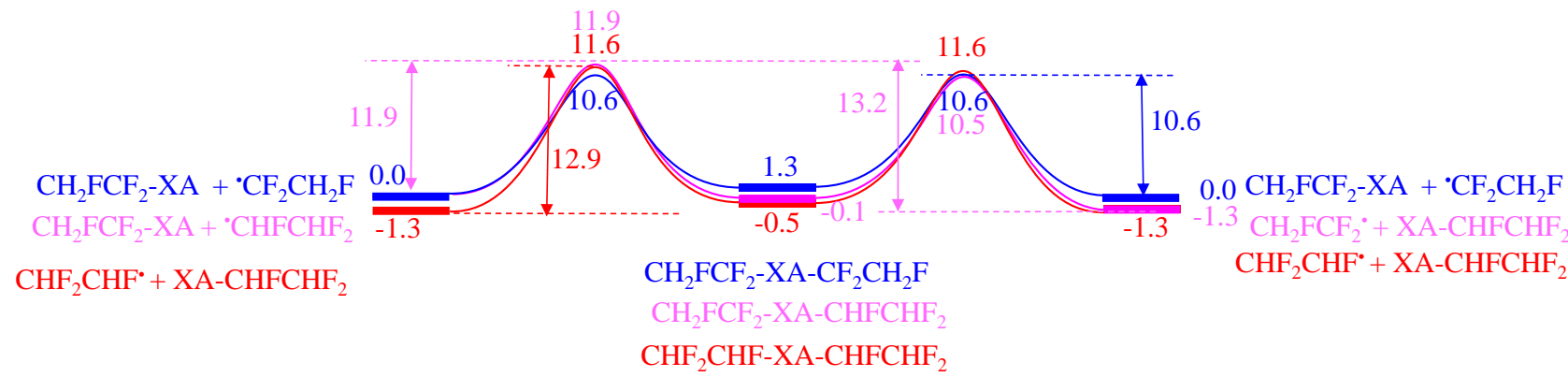

Figure 2: Energy profiles for the degenerate $(\mathrm{H} / \mathrm{H}$ and $\mathrm{T} / \mathrm{T})$ and non-degenerate $(\mathrm{H} / \mathrm{T})$ radical exchange with the dormant chain. The reported values are $\Delta \mathrm{G}^{\circ}{ }_{298.15} \mathrm{in} \mathrm{kcal} / \mathrm{mol}$

reactivated. Table S1 and S2 and Figure S2 and S3 details the evolution of the chain end functionality with and without considering the T-adducts. Here, T-adducts are considered as -CFH-XA terminated chains and are taken into account in the calculation of chain end functionnality. Dead chains, produced by hydrogen abstraction from solvent (DMC), monomer or polymer were also observed at -130 to $-134 / 6.5 \mathrm{ppm}\left(-\mathrm{CF}_{2} \mathrm{H}\right.$ termini) and $-244.6 / 5.0 \mathrm{ppm}\left(-\mathrm{CFH}_{2}\right.$ termini) in the ${ }^{19} \mathrm{~F} /{ }^{1} \mathrm{H} \mathrm{NMR}$ spectra (Figure 2), respectively.

The TrFE RAFT polymerisation kinetics and the molar mass, dispersity and chain-end resonance evolutions were monitored for two targeted degrees of polymerisation: DP50 and DP100. Table 1 gathers the data related to these experiments.

Figure 3 shows the PTrFE $\omega$ chain-end evolution (xanthate chain-ends), monitored and quantified using ${ }^{19} \mathrm{~F} N M R$ spectroscopy. As in the case of PVDF, the regularly-terminated chains (terminated by a - $\mathrm{CF}_{2}-\mathrm{XA}$ moiety and noted PTrFEH-XA) quickly disappeared from the reaction medium. Indeed, even at low TrFE conversion (around 5\%), these PTrFEн-XA chains represented already only $45 \%$ or less of the total number of chains (for both targeted DP). The precise TrFE conversion for which the PTrFEн-XA chains completely disappear is however difficult to determine. The data points shown in Figure 3 suggest that this likely occurs between 5 and $20 \%$ conversion for the DP50 experiment and between 5 and $30 \%$ conversion for the DP100 polymerization. As in the case of VDF, ${ }^{29}$ the proportion of regularly-terminated chains decreased faster with conversion when higher degrees of polymerisation were targeted (compare entries 2 and 7 in Table 1 and Figure 3). The complete disappearance of the $\mathrm{PTrFE}_{\mathrm{H}} \mathrm{XA}$ chains thus

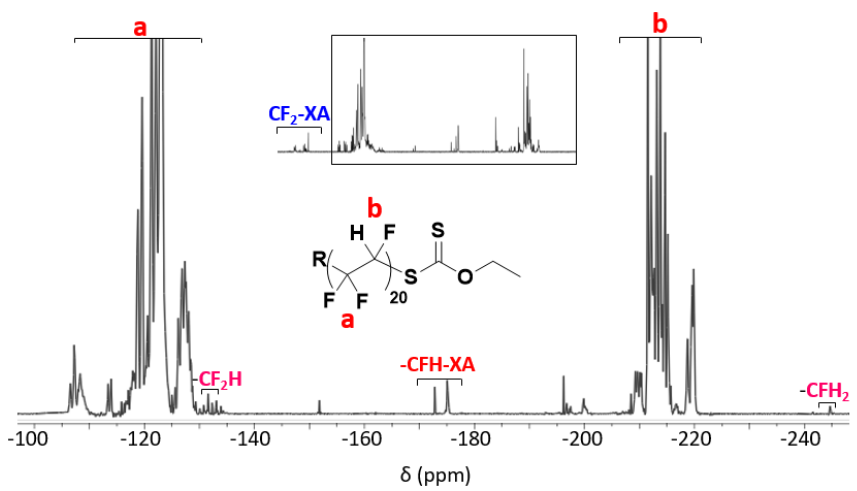

Figure $2:{ }^{19} \mathrm{~F}$ NMR spectrum of PTrFE made by RAFT (entry 5, Table 1 ) recorded in $\left(\mathrm{CD}_{3}\right)_{2} \mathrm{CO}$. likely occurs below $20 \%$ conversions in the two polymerizations studied. However, additional datapoints would be required to accurately determine these specific conversion values. Conversely, the proportion of reversely terminated PTrFE-XA chains (-CFH-XA termini, noted PTrFET$\mathrm{XA}$ and formed by transfer to a xanthate of a $\mathrm{CHF}^{\circ}$ radical) reached its maximum at low conversion with about $75 \%$ for the $\mathrm{DP}_{100}$ and as high as $95 \%$ for the $\mathrm{DP}_{50}$ experiments. The formation of these two types of xanthate-terminated chains leads to a competition between the non-degenerate and degenerate processes of chain transfer to xanthate (Figure 4). Here, as in the case of VDF, this competition induces the slowdown of the overall RAFT chain equilibrium which impairs the control of the polymerisation resulting in broader molar mass distributions. ${ }^{29}$ These PTrFET-XA chains accumulate in the reaction medium because they are less reactivatable than their PTrFE $\mathrm{H}_{\mathrm{H}} \mathrm{XA}$ counterparts. Indeed, according to DFT calculations (vide infra), the barrier for the reactivation of $\mathrm{PTrFE}_{\mathrm{H}} \mathrm{XA}$ (degenerative exchange) is lower than for $\mathrm{PTrFE}_{\mathrm{T}}$ $X A$. Again, as in the RAFT polymerisation of VDF, the overall PTrFE chain-end functionality (i.e. the proportion of xanthateterminated chains) decreased rapidly in the course of the polymerisation due to irreversible transfer reactions, and barely reached $55 \%$ or $30 \%$ after $15 \mathrm{~h}$ of polymerisation for the $\mathrm{DP}_{50}$ and $\mathrm{DP}_{100}$ experiments, respectively. Note that this functionality values also consider T-adducts; the real functionality values are actually slightly lower (50 and $25 \%$, see Tables S1 and S2 and Figures S2 and S3). This loss of

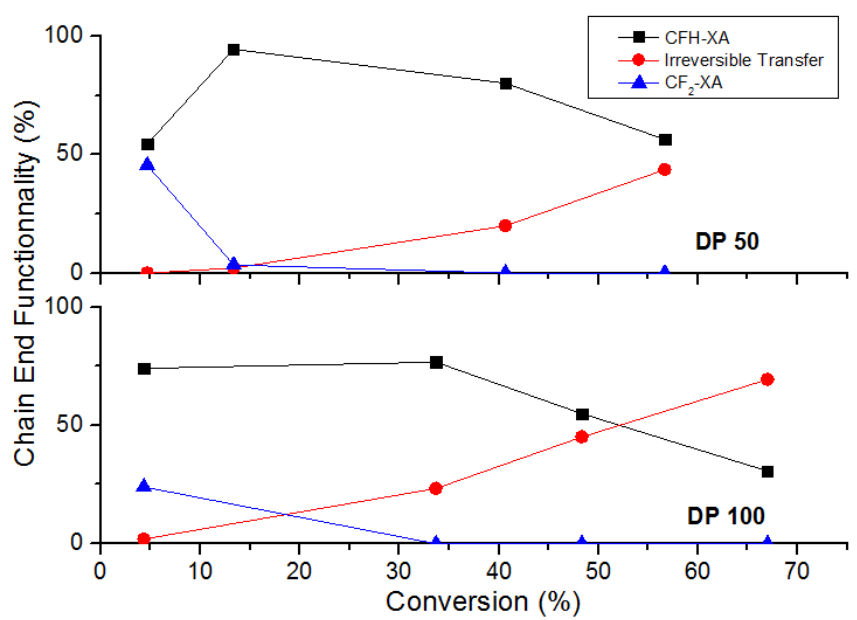

Figure 3: Evolution of the different chain ends for the RAFT polymerisation of TrFE: $\mathrm{DP}_{\text {target }}=50$ (top) and $\mathrm{DP}_{\text {target }}=100$ (bottom) calculated using Equation S1 for -CFH-XA, Equation $\mathrm{S} 2$ for $-\mathrm{CF}_{2}-\mathrm{XA}$ and Equation $\mathrm{S} 3$ for Irreversible transfer. 


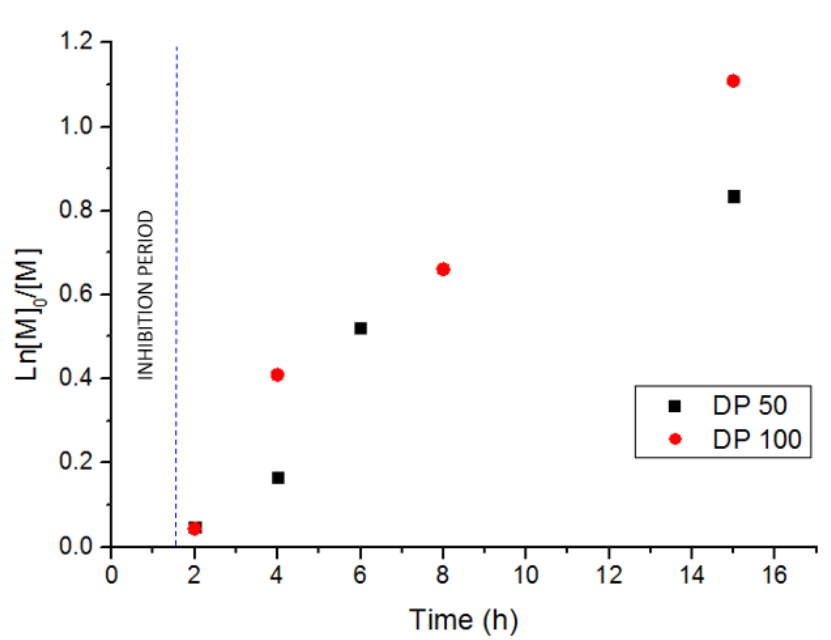

Figure 6. First-order kinetic plots of the RAFT homopolymerisation of TrFE with DPtarget $=50$ (black squares) and DPtarget $=100$ (red circles). Reaction conditions: $[\mathrm{TrFE}]_{0}:[\mathrm{CTA}]_{0}:[\mathrm{I}]_{0}=[\mathrm{DPtarget}]: 1: 0.2$. Reaction time $=15 \mathrm{~h}, \mathrm{~T}=73^{\circ} \mathrm{C}, \mathrm{CTA}=O$-ethyl$S$-(1-methoxycarbonyl)ethyldithiocarbonate, $\mathrm{I}=$ tert-amyl peroxy-2ethylhexanoate.

functional end-group is presumably caused by the strong ability of both $-\mathrm{CF}_{2}{ }^{\bullet}$ and $-\mathrm{CFH}^{\bullet}$ radicals to abstract $\mathrm{H}$ atoms.

In order to substantiate the above mechanistic interpretation, DFT calculations were carried out on a model system, at the same level of theory used for the previously reported $\mathrm{PVDF}_{\mathrm{H}-\mathrm{XA}}$ and $\mathrm{PVDF}_{\mathrm{T}} \mathrm{XA}$ reactivation investigation. ${ }^{29}$ The PTrFE $\mathrm{H}_{\mathrm{H}} \mathrm{XA}$ and $\mathrm{PTrFE}_{\mathrm{T}} \mathrm{XA}$ macro-CTAs were modelled by the $\mathrm{H}-\mathrm{CHFCF}_{2}-\mathrm{XA}$ and $\mathrm{H}-\mathrm{CF}_{2} \mathrm{CHF}-\mathrm{XA}$ molecules, in which the polymer chain beyond the xanthate-linked monomer was replaced by an $\mathrm{H}$ atom. In addition, the OEt group in the xanthate group was replaced by an OMe group. These simplifications reduce the computational cost and are not expected to introduce any major electronic change (polarity, homolytic strength) or steric effect in the bonds that are involved in the computed processes. Therefore, the calculated energy differences should not be significantly affected. The relative barriers for the additions and fragmentations relative to thedegenerate $(H / H, T / T)$ and non-degenerative $(H / T)$ exchange processes are summarised in Figure 5 . The addition barrier is the lowest for the head radical addition to the head CTA (10.6 kcal/mol, blue curve), leading to thedegenerate $\mathrm{H} / \mathrm{H}$

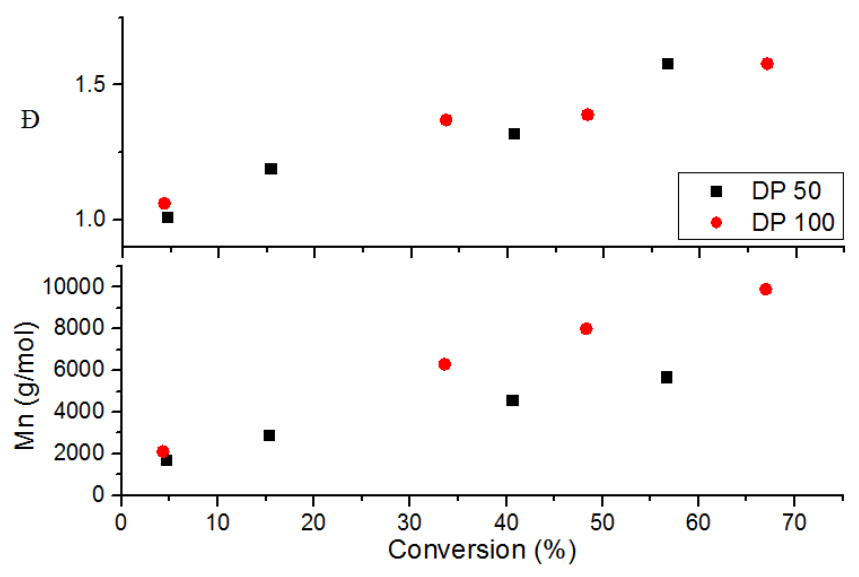

Figure 7. Evolution of the molar mass $(\mathrm{Mn})$ and the dispersity $(\Theta)$ vs conversion for the RAFT polymerisation of TrFE DP target $=50$ (black squares) and $\mathrm{DP}_{\text {target }}=100$ (red circles). Reaction conditions: $[\mathrm{TrFE}]:[\mathrm{CTA}]_{0}:[]_{0}=\left[\mathrm{DP} \mathrm{target}_{\mathrm{t}}\right]: 1: 0.2$. Reaction time $=15 \mathrm{~h}$ $\mathrm{T}=73^{\circ} \mathrm{C}, \mathrm{CTA}=\mathrm{O}$-ethyl-S-(1-methoxycarbonyl)ethyldithiocarbonate, $\mathrm{I}=$ tert-amy peroxy-2- ethylhexanoate.

exchange through an intermediate adduct that is nearly isoergic with the separate CTA and free radical. The tail radical addition to the head CTA (magenta curve) has an intermediate barrier of $11.9 \mathrm{kcal} / \mathrm{mol}$ and leads to a non-degenerative exchange, producing the head radical and the tail CTA in a slightly exoergic process $(-1.3 \mathrm{kcal} / \mathrm{mol})$. The intermediate adduct is again essentially isoergic with the separate fragments. Finally, the degenerate $T / T$ exchange (red curve) has a higher addition barrier of $12.9 \mathrm{kcal} / \mathrm{mol}$. The reverse non-degenerative exchange, corresponding to the reactivation of the tail CTA by the more abundant head free radical (magenta energy profile from right to left), has an overall activation free energy of $13.2 \mathrm{kcal} / \mathrm{mol}$ and is thus the most difficult process. These values slightly increase when calculated at $70^{\circ} \mathrm{C}$, because of a negative activation entropy (see data in the SI, Figure S4).

These trends are qualitatively similar to those previously obtained for the PVDF CTA models. ${ }^{30}$ Therefore, the calculations confirm that the inverted TrFE monomer additions lead to accumulation of less easily reactivable tail CTA (PTrFET-XA), as in the case of the VDF system. There are, however, two relevant differences. The calculations gave greater addition barriers for the TrFE system than for the VDF system (the latter were calculated as $9.0,9.0$ and $9.5 \mathrm{kcal} / \mathrm{mol}$
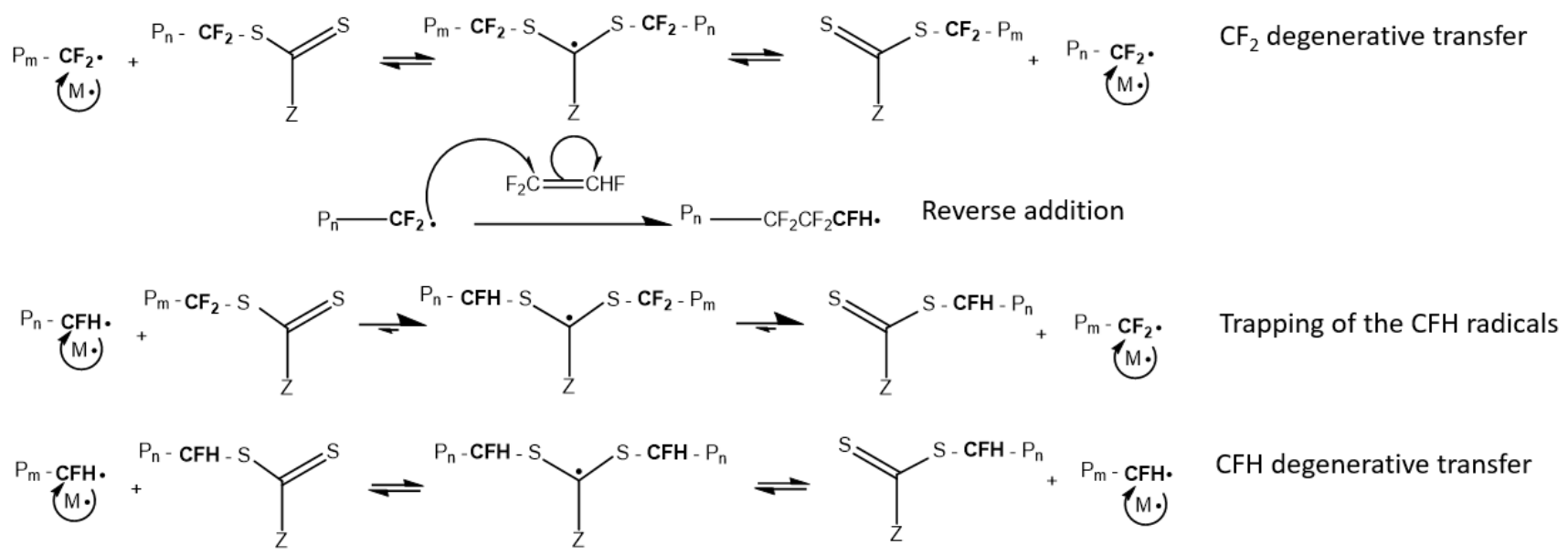

Figure 3. Scheme of the twodegenerate chain transfers and of the non-degenerative chain transfer at work during the RAFT polymerisation of TrFE. 
for the $\mathrm{H} / \mathrm{H}, \mathrm{H} / \mathrm{T}$ and $\mathrm{T} / \mathrm{T}$ processes, respectively), suggesting that the controlled polymerisation of TrFE with this RAFT chain transfer agent should be slightly less efficient. The second difference is the smaller thermodynamic gain for the non-degenerative exchange $(-1.3 \mathrm{kcal} / \mathrm{mol}$, vs. $-6.1 \mathrm{kcal} / \mathrm{mol}$ for the VDF system). Consequently, the reverse $\mathrm{T} / \mathrm{H}$ exchange has a greater barrier for the VDF system (15.1 kcal/mol). The reason for this lower thermodynamic gain is clearly related to the greater similarity of the two chain ends $\left(\mathrm{CF}_{2}\right.$ vs. CHF) relative to VDF ( $\mathrm{CF}_{2}$ vs. $\left.\mathrm{CH}_{2}\right)$. The smaller difference between the tail and head CTA reactivation barriers for TrFE may lead one to anticipate that the inverted monomer additions should have a lower impact, relative to VDF, on the loss of polymerisation control. However, this loss of control does not only depend on how fast the tail CTA is reactivated, but also on how much faster it accumulates as a consequence of the head-to-head additions. This point will be further discussed below. In light of the observed evolution of the chain end functionalities and of the DFT calculations, the kinetics (Figure 6) and the molar mass and dispersity evolutions with conversion (Figure 7) for the RAFT polymerisation of TrFE can be better interpreted.

Figure 6 shows several phases in the TrFE RAFT polymerisation. First, there is an inhibition period of around $90 \mathrm{~min}$, in which the polymerisation seemed to proceed at low speed or not at all. Inhibition periods are not unusual in RAFT polymerisation and this phenomenon was already observed in the RAFT polymerisation of VDF. ${ }^{31}$ This inhibition period might be due to the selective formation of monoadducts at the beginning of the reaction. This phenomenon has been demonstrated by Pound et al. ${ }^{40}$ when the monoadduct possesses a poor leaving group compared to the $\mathrm{R}$ group of the RAFT agent. In the present case the formation of T-adduct which are not easily reactivated by the majority $\mathrm{CF}_{2}{ }^{\bullet}$ radicals likely contribute to this inhibition. The polymerisation rate observed for the DP50 experiment seemed slower than that of the DP100 experiment. This rate retardation is also relatively common in RAFT polymerisation. ${ }^{41}$ For the DP50 experiment, the polymerisation seemed to accelerate after 4 $\mathrm{h}$. The $4 \mathrm{~h}$ mark is also the time when the PTrFE $-\mathrm{XA}$ disappeared from the reaction medium. In the case of VDF, an

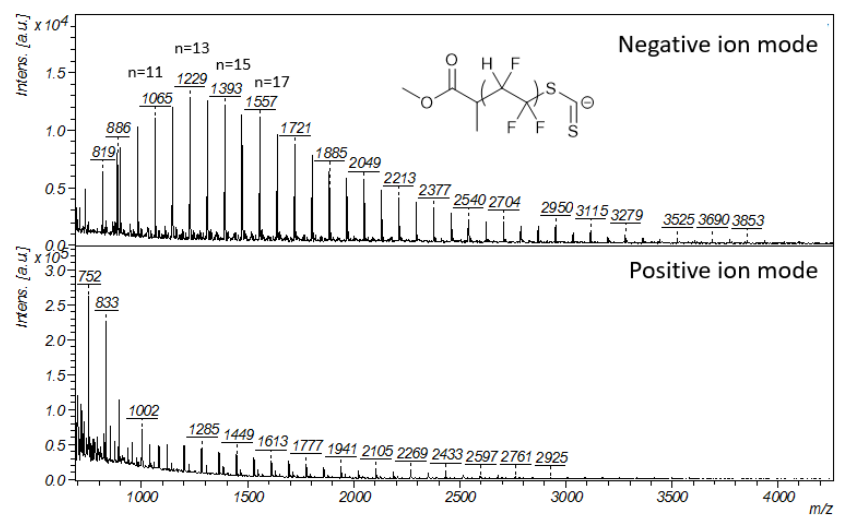

Figure 4. MALDI-TOF mass spectra in negative and positive ion mode of PTrFE prepared by RAFT polymerisation (Entry 11, Table 1). Reaction conditions: $[\mathrm{M}]_{0}:[\mathrm{CTA}]_{0}:[1]_{0}=100: 1: 0.2$, reaction time $=15 \mathrm{~h}$ at $73{ }^{\circ} \mathrm{C}$, conversion $=67 \%$. acceleration of the polymerisation was also noted when the molar fraction of $\mathrm{PVDF}_{\mathrm{H}} \mathrm{XA}$ reached zero. This rate acceleration was not observed in the DP100 experiment. This is presumably because of the lack of datapoints in this experiment. The rate acceleration likely happened in the $2 \mathrm{~h}-$ $4 \mathrm{~h}$ interval (when PTrFE $-\mathrm{XA}$ disappeared). In both experiments, a decrease of the polymerisation rate was observed towards the end of the polymerisations. This decrease of the polymerisation rate, also seen for the polymerisation of VDF, remains unclear. ${ }^{31}$ It may be caused by the decrease of the monomer concentration in solution due to the decrease of its partial pressure as the polymerisation proceeds.

At a first glance, Figure 7 seems to show a relatively linear evolution of the molar masses with conversion for both the $\mathrm{DP}_{50}$ and the $\mathrm{DP}_{100}$ polymerisations, suggesting that they are relatively well controlled. However, a slight decrease of the slope may be seen after the $4 \mathrm{~h}\left(15.3 \%, 2,900 \mathrm{~g} \mathrm{~mol}^{-1}\right)$ data point of the $\mathrm{DP}_{50}$ experiment. This point almost coincides with the total disappearance of the $\mathrm{PTrFE}_{\mathrm{H}} \mathrm{XA}$ chains. The same phenomenon was also observed for the RAFT polymerisation of VDF. ${ }^{30}$ This change of slope cannot be observed for the DP100 experiment presumably because of the lack of data points between the $4 \%$ and $33 \%$ TrFE conversion values as mentioned above. Nevertheless, the dispersity $(\boxplus)$, which remained low $(<1.2)$ in the first few hours of polymerisation, increased as the polymerisations proceeded and reached almost 1.6 at higher conversion (55-70\%). This $\bigoplus$ increase is believed to result from two causes: 1 ) irreversible transfer reactions to monomer, polymer or solvent, leading to dead chains; and 2) to the slowdown of the RAFT chain transfer process due to reverse additions. These phenomena were shown to be responsible for a similar increase of $€$ in the RAFT polymerisation of VDF. ${ }^{29-31}$

Further characterisation of the structure of the PTrFE synthesized by RAFT polymerisation (Entry 12, Table 1) was performed via matrix-assisted laser desorption/ionization coupled time-of-flight mass spectrometry (MALDI-TOF), using both positive and negative ion modes (Figure 8 and S10).

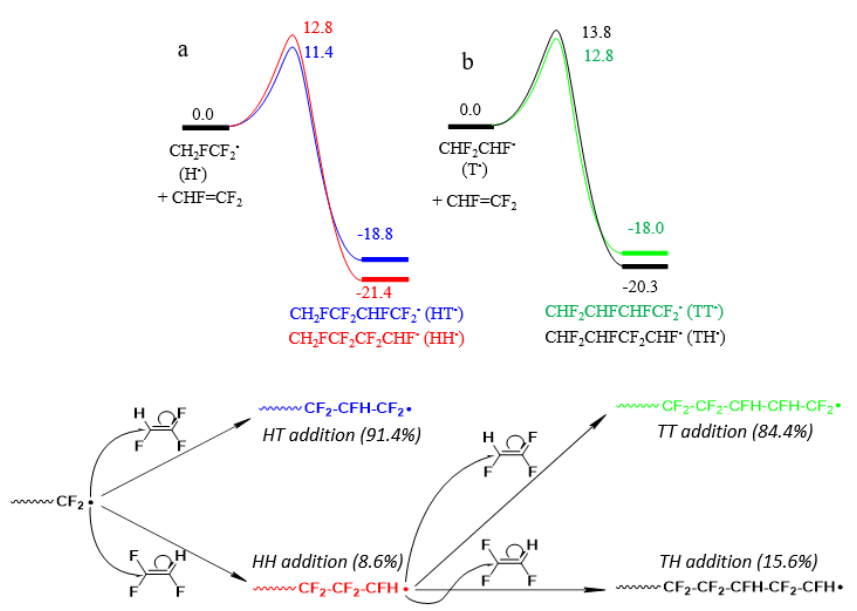

Figure 9. Detail of the four different $X A$ chain end and Energy profiles for (a) the HT and $\mathrm{HH}$ additions of the $\mathrm{PTrFE}_{\mathrm{H}} \cdot$ model radical and (b) the TH and TT additions of the $\mathrm{PTrFE}_{\mathrm{T}}{ }^{\circ}$ model radical to $\operatorname{TrFE}$. The reported values are $\Delta \mathrm{G}^{\circ}{ }_{298.15}$ (1M standard state) in $\mathrm{kcal} / \mathrm{mol}$. 
The positive ion mode showed a very weak signal and only displays the polymer chain terminated via irreversible transfer (i.e. chains terminated by $-\mathrm{CF}_{2} \mathrm{H}$ or $-\mathrm{CFH}_{2}$ ). In contrast, the negative ion mode displayed a distribution of xanthateterminated PTrFE chains centered on a DP $=13$ chain at $\mathrm{m} / \mathrm{z}=$ 1229. Note that these distributions showed a fragmentation of the relatively weak $\mathrm{C}-\mathrm{O}$ bond of the xanthate moiety presumably occuring during the analysis. Surprisingly, only the $R$ group initiated population were observed, contrary to what had been observed by Guerre et al. on PVDF made by RAFT polymerisation. ${ }^{31}$

As mentioned above, the RAFT polymerisation of TrFE faces the same problem as that of VDF: the quick formation of less reactivatable $\mathrm{PTrFE}_{\mathrm{T}} \mathrm{XA}$ chains, which are produced by headto-head $(\mathrm{HH})$ additions followed by transfer to the xanthate group. For PVDF, the HH additions are systematically followed by tail-to-tail (TT) additions and amount to about $4-4.5 \%$ of the total number of VDF additions (hence the HH-TT sequence amounts to about 8-9\% of the additions). For PTrFE, the chain defects were also believed to be constituted by $\mathrm{HH}-\mathrm{TT}$ sequences (see Introduction) and these defects were estimated by several authors to be about $13.5 \% .{ }^{14}$

To better estimate the occurrence of these chain defects and their impact on the TrFE RAFT polymerisation, a DFT approach of the radical addition onto TrFE as well as a thorough NMR study PTrFE chain-ends were carried out. The standard activation barriers associated to the four possible monomer addition modes, obtained by the DFT calculations at $25{ }^{\circ} \mathrm{C}$, are shown in Figure 9. These barriers were also calculated at $70{ }^{\circ} \mathrm{C}$ (see SI, Figure S5). The general reactivity trend is the same as that previously determined for the polymerisation of VDF (both the head and the tail radicals have lower addition barriers to the monomer tail end yielding preferential HT and TT additions, respectively). ${ }^{29}$ The energetic barrier of a HT addition is slightly lower for TrFE than for VDF, respectively $11.4 \mathrm{kcal} / \mathrm{mol}$ and $11.9 \mathrm{kcal} / \mathrm{mol}$. These values suggest a slightly faster polymerisation rate of TrFE compared to that of VDF.

For the TrFE system, the activation energy difference between the $\mathrm{HT}$ and $\mathrm{HH}$ additions is $1.4 \mathrm{kcal} / \mathrm{mol}$ at $25^{\circ} \mathrm{C}$. From this $\Delta(\Delta \mathrm{G})$, it is possible to derive a probability of occurrence of $8.6 \%$ for the $\mathrm{HH}$ additions (and $91.4 \%$ for the HT addition). This $\mathrm{HH}$ probability value is 3.6 times higher than that calculated for VDF (only $2.4 \%$ ). ${ }^{30}$ Thus, the tail dormant species, which is more difficult to reactivate as discussed above, accumulates faster for the TrFE polymerisation than for the VDF polymerisation, in agreement with the observed rapid loss of control. The activation energy difference between the TT and TH additions is only $1 \mathrm{kcal} / \mathrm{mol}$ for TrFE, vs. $4 \mathrm{kcal} / \mathrm{mol}$ at $25^{\circ} \mathrm{C}$ for VDF. This smaller difference translates into a much higher probability $(15.6 \%$, vs. $0.12 \%$ for VDF) of occurrence for the TH addition in PTrFE. At $70{ }^{\circ} \mathrm{C}$, although all Gibbs energy barriers increase, the $\Delta(\Delta \mathrm{G})$ values remain unchanged relative to $25{ }^{\circ} \mathrm{C}$ (Figure S5), but the temperature effect in the Eyring relationship slightly modifies the relative addition probabilities: $84.4 \%$ of $\mathrm{HT}$ and $15.6 \%$ of $\mathrm{HH}$ additions for the main head radical chains; $81.2 \%$ of TT and $18.8 \%$ of $\mathrm{TH}$ additions for the minor tail radical chains. These calculations thus suggest that, in addition to a much greater

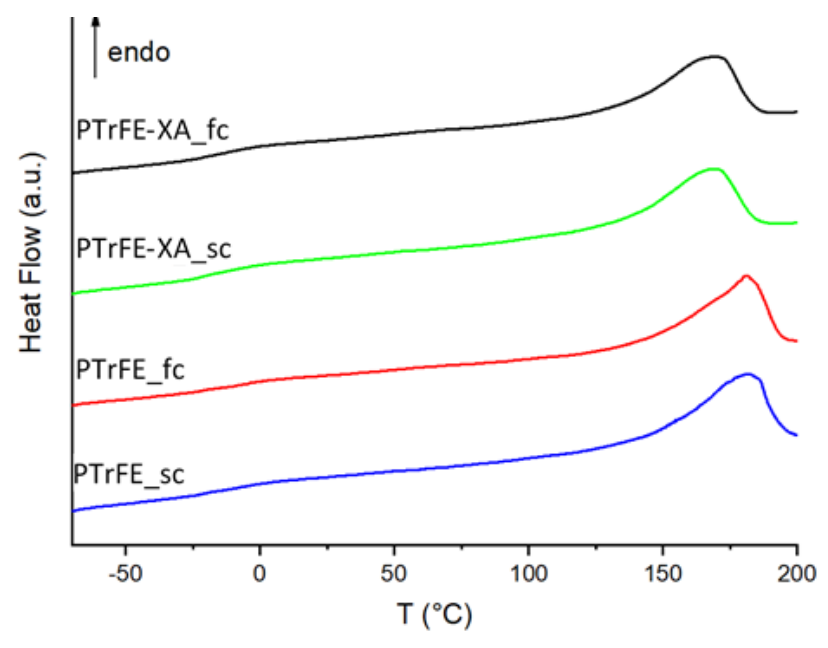

Figure 5. DSC thermogram of PTrFE-XA (made by RAFT; entry 5 table 1 ) and PTrFE (made by conventional radical polymerisation, entry 12 table 1 )) fast-cooled ( $\mathrm{fc}$ ) and slow-cooled (sc) from the melt.

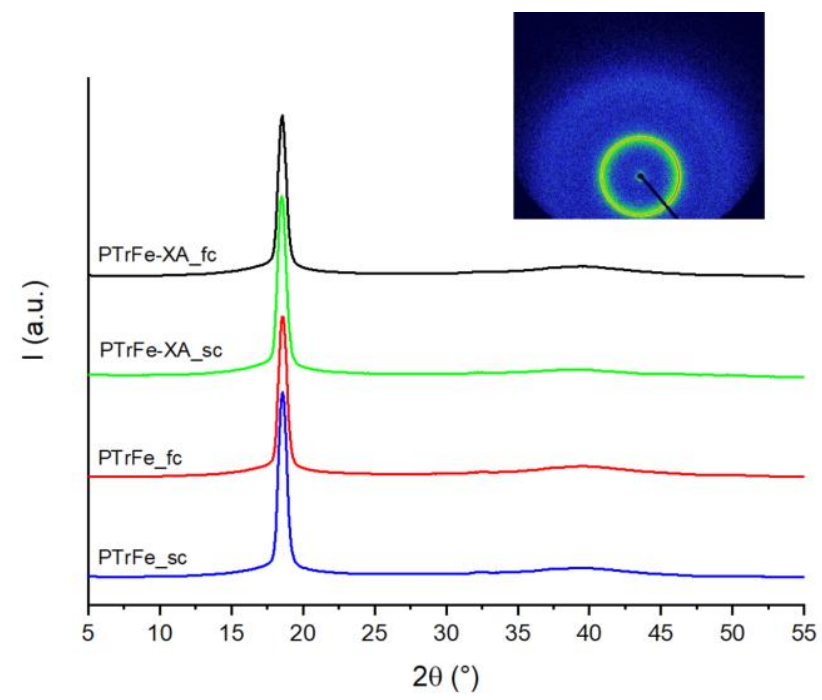

Figure 12. WAXS patterns and intensity profiles of slow-cooled (sc) and fast-cooled (fc) PTrFE (Entry 12, Table 1) and PTrFE-XA (Entry 5, Table 1).

impact of the monomer addition errors for the TrFE polymerisation, the $\mathrm{HH}$ additions are not systematically followed by a TT addition. A non-negligible fraction of $\mathrm{HH}-\mathrm{TH}$ (- $\mathrm{CHFCF}_{2}-\mathrm{CF}_{2} \mathrm{CHF}_{-} \mathrm{CF}_{2} \mathrm{CHF}-$ ) sequences may be generated. To the best of our knowledge, only Yagi reported the possibility of TH addition in PTrFE, ${ }^{10}$ whereas all the subsequent studies on PTrFE considered that $\mathrm{HH}$ additions were systematically followed by a TT addition. However, the probability of two consecutive $\mathrm{TH}$ additions, as calculated from the probabilities of $\mathrm{HH}$ and $\mathrm{TH}$ additions under the terminal model approximation, is only $1.3 \%$ at $25^{\circ} \mathrm{C}$ or $2.1 \%$ at $70^{\circ} \mathrm{C}$. The conclusion is that two main types of chain defects should exist in PTrFE: the most probable one derived from $\mathrm{HH}$-TT addition sequence $\left(7.3 \%\right.$ of the triads at $25{ }^{\circ} \mathrm{C}, 9.25 \%$ at $\left.70{ }^{\circ} \mathrm{C}\right)$ and a less important one derived from the $\mathrm{HH}-\mathrm{TH}$ addition sequence.

The experimental proof of the existence of these TH additions was so far missing since NMR spectroscopy is not directional and cannot distinguish between $\mathrm{HT}$ and $\mathrm{TH}$ additions (leading to $-\mathrm{CHFCF}_{2}-\mathrm{CHFCF}_{2}$ - or to $-\mathrm{CF}_{2} \mathrm{CHF}_{-} \mathrm{CF}_{2}-\mathrm{CHF}$ motifs respectively). A thorough examination of the ${ }^{1} \mathrm{H}$ and ${ }^{19} \mathrm{~F}$ NMR 
spectra of PTrFE prepared by RAFT polymerisation was thus carried out. This study, detailed in a different article $^{39}$, has evidenced the existence of a - CFH-XA chain end where the $\mathrm{CFH}$ group ${ }^{19} \mathrm{~F}$ NMR resonance at $-174.9 \mathrm{ppm}$ is correlated in ${ }^{3} \mathrm{~J}_{\mathrm{F}-\mathrm{F}}$ with the resonance of a $\mathrm{CF}_{2}$ group and in ${ }^{4} \mathrm{~J}_{\mathrm{F}-\mathrm{F}}$ with that of a $\mathrm{CFH}$ group, proving the existence of a $\mathrm{CFH}^{*}$ radical resulting from a TH addition or in other words, to a reversed propagation (Figure S9).

Finally, two samples of PTrFE (made by RAFT and by conventional free radical polymerisation and indicated as PTrFE-XA and PTrFE, respectively, see Table S4) were heated to $210^{\circ} \mathrm{C}$ and cooled down from the melt either by fast cooling (around $1000^{\circ} \mathrm{C} / \mathrm{min}$ ) or by slow cooling $\left(<2^{\circ} \mathrm{C} / \mathrm{min}\right)$, trying to reproduce the work of Oka et al. ${ }^{8}$ The DSC thermograms of the samples presented in Figure 11 do not show any significant differences for the different cooling rates. The heat capacity jump attributed to the glass transition temperature $\left(T_{g}\right)$ is located around $-23^{\circ} \mathrm{C}$ for both PTrFE samples and the endothermic peak characteristic of the melting of the primary crystals $\left(T_{m}\right)$ is observed at around $168^{\circ} \mathrm{C}$ for PTrFE-XA and at around $181^{\circ} \mathrm{C}$ for PTrFE. It is interesting to note the higher melting temperature for the PTrFE sample prepared by conventional polymerisation. This can be explained the presence of longer macromolecular chainswhich induce the formation of crystalline domains. Because of the relatively low molar mass of both polymers, the melt temperatures are much lower than the values of $213^{\circ} \mathrm{C}$ or between $186^{\circ} \mathrm{C}$ and $194^{\circ} \mathrm{C}$ reported in the literature. ${ }^{26,42,43}$

In order to identify the PTrFE crystal phase, the structure was investigated by WAXS at ambient temperature. A representative scattering pattern of PTrFE and the associated integrated intensity profiles are depicted in F. For all samples, the WAXS pattern is a ring characteristic of an isotropic distribution of the macromolecular chains. The corresponding intensity profile presents a main peak at $2 \theta=18.2^{\circ}$ and two smaller peaks at $2 \theta=31.8$ and $36.7^{\circ}$ associated to the (100), (110) and (200) planes, respectively, and characteristic to the non-polar crystal phase of PTrFE. ${ }^{27,44}$ No difference was established between the two different cooling rates and the crystal phase does not show any trace of the polar phase responsible for the ferroelectric behaviour of those polymers. This behaviour may also be caused by the relative low molar masses of the PTrFE examined.

\section{Conclusions}

This work shows that xanthates are suitable chain transfer agent for the RAFT polymerisation of trifluotroethylene (TrFE). However, as in the case of vinylidene fluoride (VDF), the RAFT mechanism is adversely affected by: 1 ) irreversible transfer caused by the strong propensity of PTrFE radicals for $\mathrm{H}$-abstraction, and 2) reverse monomer additions (head-tohead, $\mathrm{HH}$ ), leading to the formation of less reactive chain ends that slow down the RAFT chain equilibrium. These effects, which lead to a loss of polymerisation control, are even more pronounced with TrFE than with VDF, because TrFE is much more prone to reverse additions. In consequence, welldefined PTrFE may only be prepared, in solution, at low conversions before irreversible transfer becomes dominant. Polymerisation in dispersed aqueous media may partially alleviate this problem. However, the RAFT equilibrium slowdown problem, which is inherent to the $\mathrm{HH}$ addition probability, may not have a solution. Organometallicmediated radical polymerisation and specifically cobaltmediated radical polymerisation would probably reactivate both chain-ends and afford higher molar masses and better control over the polymerisation. ${ }^{45,46}$ Nevertheless, thanks to the ability of the RAFT polymerisation to temporarily trap endgroups, the chain-end evolution monitoring during the RAFT polymerisation, combined with DFT calculations, led to the discovery of limited reverse (tail-to-head) propagation. This behaviour seems, so far, unique to TrFE; the $\mathrm{HH}$ additions are systematically followed by $T T$ additions in the VDF polymerisation. This work provides a much better understanding of the polymerisation behaviour of TrFE, paves the way to the study of the RAFT copolymerisation of VDF and TrFE, and provides important information to decipher the microstructure of important TrFE-containing electroactive fluoropolymers.

\section{Author Contributions}

Vincent BOUAD: Conceptualization, Methodology, Validation, Investigation, Writing Original Draft, Review \& Editing. Marc GUERRE: Conceptualization, Methodology. Cédric TOTEE: Methodology. Gilles SILLY: Methodology. Olinda GIMELLO: Investigation. Bruno AMEDURI: Writing Review \& Editing. JeanFrançois TAHON: Investigation. Rinaldo POLI: Methodology, Software, Formal analysis, Writing - Review \& Editing. Sophie BARRAU: Methodology, Validation, Investigation, Writing Original Draft, Review \& Editing, Supervision, Funding acquisition. Vincent LADMIRAL: Conceptualization, Methodology, Writing Original draft, Review \& Editing, Supervision, Funding acquisition.

\section{Conflicts of interest}

There are no conflicts to declare

\section{Acknowledgements}

This work was partly supported through grant ANR-16-CE080025, ANR NanoPiC from the French National Research Agency. The authors thank Arkema (Pierre Bénite, France) for providing TrFE.

\section{Notes and references}

11 John Scheirs, Polym. Int., 1999, 426, 8103.

2 B. Boutevin and B. Ameduri, Well-Architectured Fluoropolymers: Synthesis, Properties, and Applications, 2004.

3 G. J. Puts, P. Crouse and B. M. Ameduri, Chem. Rev., 2019, 119, 1763-1805.

4 B. Ameduri and S. Fomin, Fascinating Fluoropolymers and their Applications, 2020. 

39, 164-198. Dos Santos and B. Ameduri, Macromolecules, 2015, 48, 7861-7871. Y. Oka and N. Koizumi, Jpn. J. Appl. Phys., 1984, 23, 748-753. Y. Oka, N. Koizumi and Y. Murata, J. Polym. Sci. Part B Polym. Phys., 1986, 24, 2059-2072. R. E. Naylor and S. W. Lasoski, J. Polym. Sci., 1960, 44, 1-7. T. Yagi, Polym. J., 1979, 11, 353-358. A. E. Tonelli, F. C. Schilling and R. E. Cais, Macromolecules, 1982, 15, 849-853.

Macromolecules, 1981, 14, 560-564.

A. E. Tonelli, F. C. Schilling and R. E. Cais, in Advances in Chemistry Series, 1983, pp. 441-454.

\section{S. A. Reinsberg, S. Ando and R. K. Harris, Polymer} (Guildf)., 2000, 41, 3729-3736.

R. E. Cais and J. M. Kometani, Macromolecules, 1984, 17, 1932-1939.

A. J. Lovinger and R. E. Cais, Macromolecules, 1984, 17, 1939-1945.

S. A. Mohammad, S. Shingdilwar, S. Banerjee and B. Ameduri, Prog. Polym. Sci., 2020, 106, 101255.

J. F. Harris and F. W. Stacey, J. Am. Chem. Soc., 1963, 85, 749-754.

J. F. Harris and F. W. Stacey, J. Am. Chem. Soc., 1961, 83, 840-845.

G. Haran and D. W. A. Sharp, J. Chem. Soc. Perkin Trans. 1, 1972, 34.

B. Ameduri, B. Boutevin, M. Kharroubi, G. Kostov and P. Petrova, J. Fluor. Chem., 1998, 91, 41-48.

A. Coscia, J. Org. Chem., 1961, 26, 2995-2996.

P. Tarrant and A. M. Lovelace, J. Am. Chem. Soc., 1955, 77, 768-770.

J. Balagué, B. Améduri, B. Boutevin and G. Caporiccio, J. Fluor. Chem., 1995, 73, 237-245.

S. Gosset, A. Alaaeddine, O. Gimello, V. Ladmiral and B. Ameduri, J. Fluor. Chem., 2016, 183, 74-81. M. Colpaert, S. Banerjee, V. Ladmiral, T. Ono and B. Améduri, Polym. Chem., 2018, 9, 894-903. K. Tashiro, K. Takano, M. Kobayashi, Y. Chatani and H. Tadokoro, Ferroelectrics, 1984, 57, 297-326. Y. Murata and N. Koizumi, Polym. J., 1985, 17, 385391.

M. Guerre, G. Lopez, T. Soulestin, C. Totée, B. Améduri, G. Silly and V. Ladmiral, Macromol. Chem. Phys., 2016, 217, 2275-2285.

M. Guerre, S. M. W. Rahaman, B. Améduri, R. Poli and V. Ladmiral, Macromolecules, 2016, 49, 53865396.

M. Guerre, B. Campagne, O. Gimello, K. Parra, B. Ameduri and V. Ladmiral, Macromolecules, 2015, 48, 7810-7822.

X. Liu, O. Coutelier, S. Harrisson, T. Tassaing, J. D. Marty and M. Destarac, ACS Macro Lett., 2015, 4, 89-93.
X. Li, E. F. McCord, S. Baiagern, P. Fox, J. L. Howell, S. K. Sahoo and P. L. Rinaldi, Magn. Reson. Chem., 2011, 49, 413-424.

M. J. Frisch, G. W. Trucks, H. B. Schlegel, G. E. Scuseria, M. A. Robb, J. R. Cheeseman, G. Scalmani, V. Barone, G. A. Petersson, H. Nakatsuji, X. Li, M. Caricato, A. V. Marenich, J. Bloino, B. G. Janesko, R. Gomperts, B. Mennucci, H. P. Hratchian, J. V. Ortiz, A. F. Izmaylov, J. L. Sonnenberg, D. Williams-Young, F. Ding, F. Lipparini, F. Egidi, J. Goings, B. Peng, A. Petrone, T. Henderson, D. Ranasinghe, V. G. Zakrzewski, J. Gao, N. Rega, G. Zheng, W. Liang, M. Hada, M. Ehara, K. Toyota, R. Fukuda, J. Hasegawa, M. Ishida, T. Nakajima, Y. Honda, O. Kitao, H. Nakai, T. Vreven, K. Throssell, J. J. A. Montgomery, J. E. Peralta, F. Ogliaro, M. J. Bearpark, J. J. Heyd, E. N. Brothers, K. N. Kudin, V. N. Staroverov, T. A. Keith, R. Kobayashi, J. Normand, K. Raghavachari, A. P. Rendell, J. C. Burant, S. S. lyengar, J. Tomasi, M. Cossi, J. M. Millam, M. Klene, C. Adamo, R. Cammi, J. W. Ochterski, R. L. Martin, K. Morokuma, O. Farkas, J. B. Foresman and D. J. Fox, 2016, Gaussian 16, Revision B.01. V. S. Bryantsev, M. S. Diallo and W. A. Goddard, J. Phys. Chem. B, 2008, 112, 9709-9719.

A. D. Asandei, O. I. Adebolu and C. P. Simpson, J. Am. Chem. Soc., 2012, 134, 6080-6083.

37 C. Boyer, D. Valade, L. Sauguet, B. Ameduri and B. Boutevin, Macromolecules, 2005, 38, 10353-10362. A. D. Asandei, O. I. Adebolu, C. P. Simpson and J. S. Kim, Angew. Chemie - Int. Ed., 2013, 52, 1002710030.

V. Bouad, M. Guerre, S. Zeliouche, C. Totée, G. Silly, B. Améduri, R. Poli, V. Ladmiral* and Trifluoroethylene, Polym. Chem. G. Pound, J. B. McLeary, J. M. McKenzie, R. F. M. Lange and B. Klumperman, Macromolecules, 2006, 39, 7796-7797.

S. Perrier and P. Takolpuckdee, J. Polym. Sci. Part A Polym. Chem., 2005, 43, 5347-5393. Y. Toshiharu, T. Masayoshi and S. Jun-Ichi, Polym. J., 1980, 12, 209-223. K. Loufakis and B. Wunderlich, Macromolecules, 1987, 20, 2474-2478. R. R. Kolda and J. B. Lando, J. Macromol. Sci. Part B, 1975, 11, 21-39. S. Banerjee, V. Ladmiral, A. Debuigne, C. Detrembleur, R. Poli and B. Améduri, Angew. Chemie - Int. Ed., 2018, 57, 2934-2937. 